\title{
Collision Tumor of a Squamous Cell Carcinoma and Adenoid Cystic Carcinoma in Mobile Tongue
}

\author{
Xiaoyan Liao, $\mathrm{MD}, \mathrm{PhD}^{1}$, Joel B. Fontanarosa, $\mathrm{MD}$, $\mathrm{PhD}^{2}$, Dongwei Zhang, $\mathrm{MD}, \mathrm{PhD}^{1 *}$ \\ ${ }^{1}$ Department of Pathology and Laboratory Medicine, University of Rochester Medical Center, Rochester, NY, USA \\ ${ }^{2}$ Department of Otolaryngology, University of Rochester Medical Center, Rochester, NY, USA
}

${ }^{*}$ Corresponding Author: Dongwei Zhang, Department of Pathology and Laboratory Medicine, University of Rochester Medical Center, Rochester, NY, USA; E-mail: dongwei_zhang@urmc.rochester.edu

Received: December 10, 2019; Accepted: January 28, 2020; Published: February 17, 2020

\begin{abstract}
Malignant neoplasms in tongue are mainly squamous cell carcinomas (SCCs). Adenoid cystic carcinoma (AdCC) in mobile tongue is extremely rare, with a reported incidence of approximately $3 \%$. Here we report a collision tumor of SCC and AdCC in an 88-year-old female with an ulcerative white lesion on the left lateral tongue. A computed tomography scan of the neck demonstrated a $2.0 \mathrm{~cm}$ mass with $0.6 \mathrm{~cm}$ radiologic depth of invasion. Complete examination of the lesion demonstrated a collision tumor consisting of SCC and AdCC which were close to each other but clearly separated. Histomorphological and immunohistochemical studies confirmed the two distinct tumor entities. To our knowledge, this is the first case of collision tumor of SCC and AdCC in the mobile tongue in which two distinct carcinoma entities were identified in this lesion. A diagnosis of this collision tumor can only be reached by complete histological examination of the lesion after surgical resection. Surgery is the choice of the treatment. Both tumor types need to be considered for therapeutic strategy and long-term follow-up is mandatory.
\end{abstract}

Keywords: Collision tumor, squamous cell carcinoma, adenoid cystic carcinoma, mobile tongue

\section{Introduction}

The most common type of malignant neoplasms in head and neck including tongue is squamous cell carcinomas (SCC). The two major causes of SCC are (1) tobacco, alcohol, and (2) human papillomavirus [1]. Adenoid cystic carcinoma (AdCC) is an infrequent malignant neoplasm and accounts for $1 \%$ of all head and neck malignancies and $10 \%$ of all salivary gland malignancies [2,3]. AdCC can occur in both major and minor salivary glands. The most common intraoral site for AdCC is the hard palate, followed by the base of the tongue. The presentation rate of AdCC in the base of the tongue is 8.8\% [4-6]. AdCC in mobile tongue is extremely rare, with a reported incidence of only approximately 3\% [7-9]. The optimal treatment for patients with AdCC is surgery and adjuvant radiation therapy, with a 5-year cause-specific overall survival rates of $74 \%[10,11]$. Here we report a collision tumor of SCC and AdCC in mobile tongue, which has never been described before.

\section{Case Report}

An 88-year-old female patient with past medical history of dementia and hypertension presented with an ulcerative white lesion on the left side of lateral tongue. She had pain with swallowing. She was a former smoker (quit in her 20s). Several her family members had a history of throat cancer. A computed tomography (CT) scan of the neck demonstrated a $2.0 \mathrm{~cm}$ mass-like enhancement in the left lateral oral tongue, with an approximate $0.6 \mathrm{~cm}$ radiologic depth of invasion, suspicious for a primary oral tongue malignancy (Figure
1A). No cervical lymphadenopathy was identified. Laryngoscopy was performed and intraoperative frozen section suggested squamous cell carcinoma. The patient subsequently underwent partial glossectomy.

Macroscopically, a red-brown to gray-white ulcerated lesion was identified in the lateral tongue. Microscopic examination demonstrates a moderately differentiated keratinizing squamous cell carcinoma with a depth of invasion of $8 \mathrm{~mm}$. However, adjacent to this classical squamous cell carcinoma, a morphologically distinct subepithelial tumor $(0.5 \mathrm{~cm}$ in greatest dimension) was identified consisting of basaloid cells with tubular and cribriform growth patterns, morphologically consistent with AdCC. No mitosis or necrosis was identified in this small tumor (Figure 1 B-D).

Immunohistochemically, the tumor cells were strongly positive for c-KIT and SOX10. The ductal epithelial cells were positive for CK7; and the abluminal cells were positive for p63 and SMA (Figure 2). Ki67 proliferation index was approximately $15 \%$. The immunoprofile confirms a diagnosis of AdCC. Thus, this whole lesion was classified as a collision tumor of SCC and AdCC.

\section{Discussion}

SCC accounts for $>90 \%$ of all oral cavity malignancies. Among them, tongue (lateral and ventral) accounts for $>50 \%$ of cases. SCC is most commonly seen in elderly patients, and is associated with tobacco and alcohol use. AdCC of the salivary gland is a malignant epithelial tumor with epithelial and myoepithelial cells arranged in tubular, cribriform, and solid forms. It is seen in elderly patients with 
slight female predominance. AdCC arising from minor salivary glands of mobile tongue is extremely rare, with only few cases reported in the literature. Here we report the first case of collision tumor consisting of distinct components of conventional keratinizing SCC and AdCC, which were close to each other but clearly separated in the mobile tongue. Since AdCC is a small focus, it can easily be missed if the specimen was not entirely examined. Indeed, during frozen section, only the area of SCC but not AdCC was sampled.
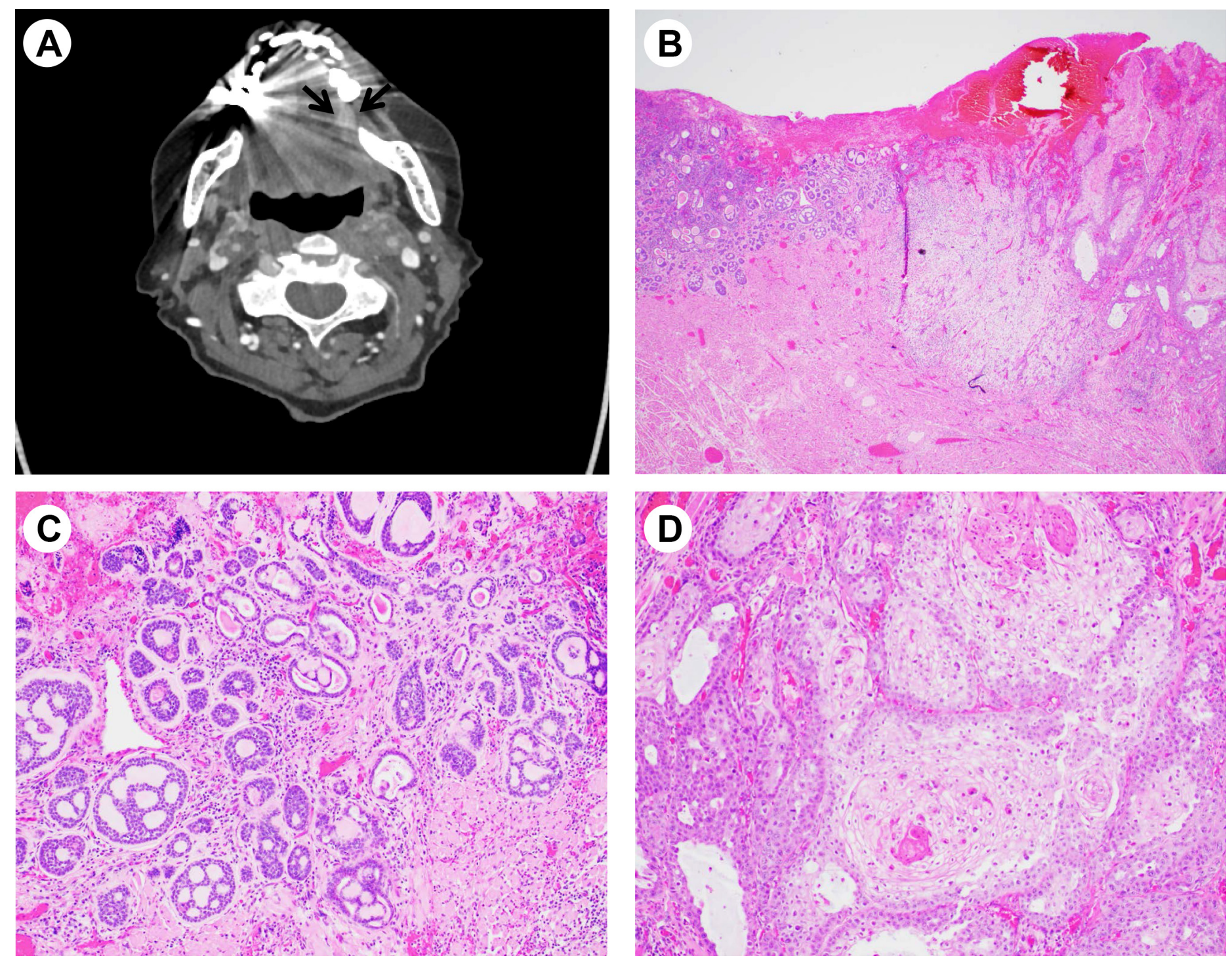

Figure 1. Imaging and histologic features of collision tumor. (A) Computed tomography imaging showing a $2.0 \mathrm{~cm}$ mass like enhancement (arrows) in the left lateral oral tongue. (B) Low magnification (hematoxylin-eosin stain, x20) showing collision tumor consisting of an adenoid cystic carcinoma (left) and conventional keratinizing squamous cell carcinoma (right). (C) High magnification $(\times 100)$ showing adenoid cystic carcinoma. (D) High magnification $(\times 100)$ showing squamous cell carcinoma.

AdCC is a rare neoplasm and not difficult to diagnosis in most cases. However, it can pose great challenge when it presents as part of a collision tumor like our case. AdCC typically has an infiltrative growth pattern that can destroy salivary gland tissue and invade into fat, skeletal muscle and soft tissue. The tumor is usually ill defined, unencapsulated with a firm, white-gray cut surface. Histologically, AdCC consists of small to medium basaloid tumor cells with scant eosinophilic to clear cytoplasm and basophilic angulated nuclei, with cribriform, solid, trabecular or tubular growth patterns. Mitotic features or necrosis are rarely seen. Immunohistochemical stains are helpful, showing tumor cells to be strongly positive for c-KIT while the ductal epithelial cells to be positive for cytokeratins. The basaloid abluminal cells are positive for myoepithelial cell markers such as p63, SMA and calponin [12]. Molecular or cytogenetics can be helpful, as $40-80 \%$ of AdCC is characterized by $\mathrm{t}(6 ; 9)$ (q22-23;p23-24) translocations resulting in MYB-NFIB gene fusion. We have tested MYB fusion by FISH in our case and it is negative. MYB-NFIB gene fusion indicates poor prognosis [13].

The differential diagnosis of AdCC, particularly in this case, includes mainly other malignant salivary gland neoplasms with basaloid cells and cribriform growth patterns, such as polymorphous adenocarcinoma, basal cell adenocarcinoma, or basaloid SCC. Polymorphous adenocarcinoma is an uncommon malignant epithelial neoplasm consisting of uniformly bland, round to polygonal tumor 
cells with infiltrative growth. It can have tubular or cribriform patterns. The tumor has a unique $\mathrm{p} 63+/ \mathrm{p} 40$ - immunophenotype that helps distinguish it from AdCC [14]. Basal cell adenocarcinoma is a malignant basaloid salivary gland neoplasm showing epithelial and myoepithelial differentiation with invasion and sometime metastasis. It most commonly involves the parotid gland but is rarely seen in tongue. Basal cell adenocarcinoma shows well-developed peripheral palisading and consists of two cell populations: peripheral small dark basaloid cells and central large polygonal cells [15]. Basaloid SCC is a high-grade variant SCC composed of infiltrative basaloid cells and variable squamous component. Presence of squamous differentiation such as keratinization, squamous dysplasia, SCC in situ, or invasive SCC should raise suspicion against diagnosis of AdCC even in presence of cribriform growth [16].
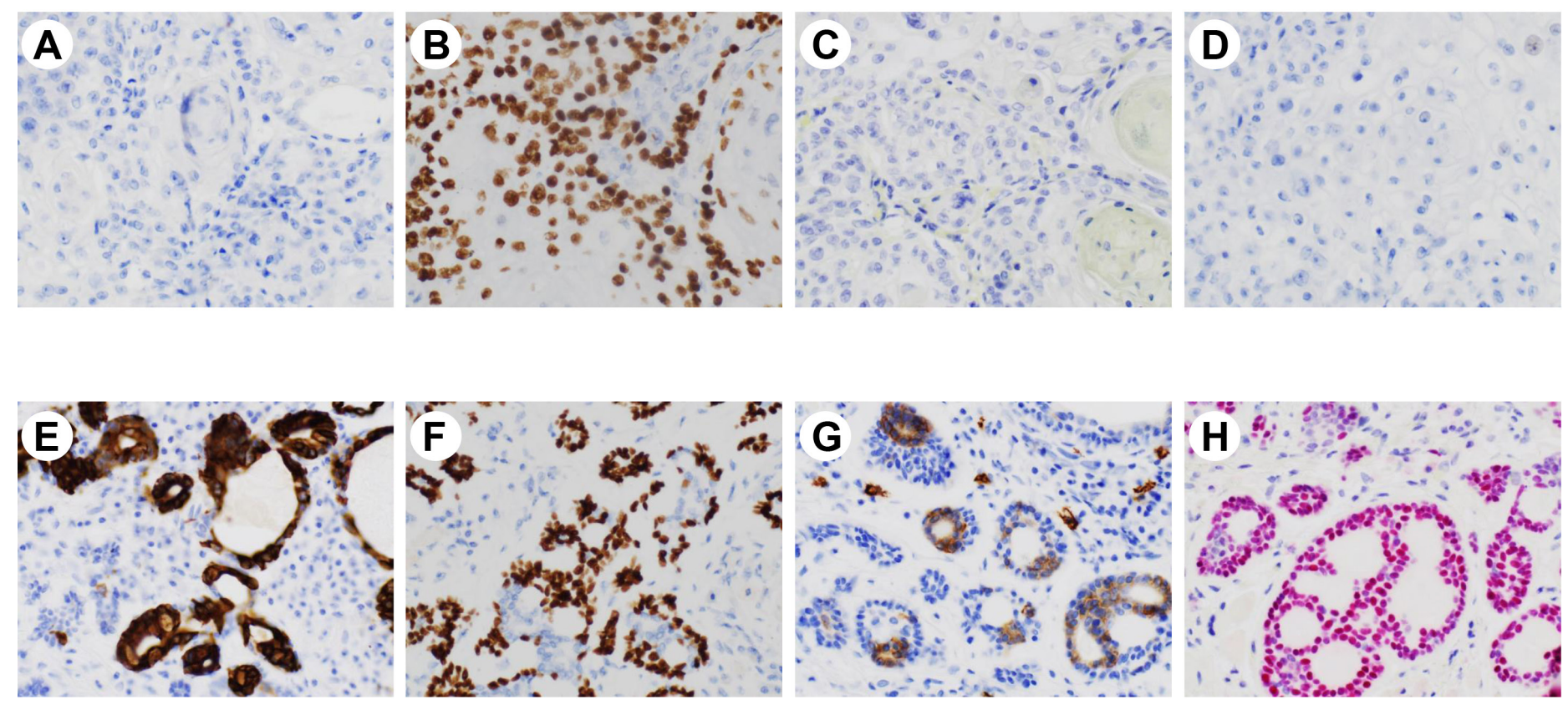

Figure 2. Immunohistochemical stains performed on squamous cell carcinoma (upper panel, A-D) and adenoid cystic carcinoma (lower panel, E-H) (A\&E: cytokeratin 7, B\&F: p63, C\&G: c-KIT, D\&H: SOX10; magnifications $\times 200$ ).

In summary, we present the first case of collision tumor consisting of a conventional keratinizing SCC and AdCC. A diagnosis of this collision tumor can only be reached by complete histological examination of the lesion after surgical resection. Surgery is the choice of the treatment. Both tumor types need to be considered for therapeutic strategy and long-term follow-up is mandatory.

\section{References}

1. Rettig EM, D'Souza G: : (2015) Epidemiology of head and neck cancer. Surg Oncol Clin N Am. 24: 379-396 [Crossref]

2. Spiro RH, Huvos AG, Strong EW. (1974) Adenoid cystic carcinoma of salivary origin. A clinicopathologic study of 242 cases. Am J Surg. 128: 512-520 [Crossref]

3. P.J. Bradley, (2004) Adenoid cystic carcinoma of the head and neck: a review Curr Opin Otolaryngol Head Neck Surg. 12: 127-132 [Crossref]

4. Luna-Ortiz K, Carmona-Luna T, (2009) Cano-Valdez AM, Mosqueda-Taylor A, Herrera-Gómez A, Villavicencio-Valencia VV. Adenoid cystic carcinoma of the tongue clinicopathologic study and survival analysis. Head Neck Oncol. 1: 15 [Crossref]

5. Soares EC, Carreiro Filho FP, Costa FW, Vieira AC, Alves AP. (2008) Adenoid cystic carcinoma of the tongue: Case report and literature review. Med Oral Patol Oral Cir Bucal. 13: E475-478

6. Ustündag E, Iseri M, Aydin O, Dal H, Almaç A, Paksoy N. (2000) Adenoid cystic carcinoma of the tongue. J Laryngol Otol. 114: 477-480

7. Baskaran P, Mithra R, Sathyakumar M, Misra S. (2012) Adenoid cystic carcinoma of the mobile tongue: A rare case. Dent Res J (Isfahan). 9 Suppl 1: S115-118 [Crossref]

8. Kumar S, Agarwal P, Nimmi V. Adenoid cystic carcinoma: A rare late presentation of the mobile tongue. J Oral Biol Craniofac Res. 2016; 6: 164-167 [Crossref]
9. Patnayak R, Jena A, Inamdar MB, Reddy GV, Appasani S, Bodagala V. (2016) Adenoid cystic carcinoma of mobile tongue. Int J Oral Health Sci. 6: 92-95

10. Silverman DA, Carlson TP, Khuntia D, Bergstrom RT, Saxton J, Esclamado RM. (2004) Role for postoperative radiation therapy in adenoid cystic carcinoma of the head and neck. Laryngoscope. 114: 1194-1199 [Crossref]

11. Mendenhall WM, Morris CG, Amdur RJ, Werning JW, Hinerman RW, Villaret DB. (2004) Radiotherapy alone or combined with surgery for adenoid cystic carcinoma of the head and neck. Head Neck. 26: 154-162 [Crossref]

12. Jaso J, Malhotra R. (2011) Adenoid cystic carcinoma. Arch Pathol Lab Med. 135: 511-515 [Crossref]

13. Persson M, Andrén Y, Mark J, Horlings HM, Persson F, Stenman G. (2009) Recurrent fusion of MYB and NFIB transcription factor genes in carcinomas of the breast and head and neck. Proc Natl Acad Sci U S A. 106: 18740-18744 [Crossref]

14. Rooper L, Sharma R, Bishop JA. (2015) Polymorphous low grade adenocarcinoma has a consistent $\mathrm{p} 63+/ \mathrm{p} 40$ - immunophenotype that helps distinguish it from adenoid cystic carcinoma and cellular pleomorphic adenoma. Head Neck Pathol. 9: 79-84 [Crossref]

15. Cuthbertson DW, Raol N, Hicks J, Green L, Parke R. (2015) Minor salivary gland basal cell adenocarcinoma: a systematic review and report of a new case. JAMA Otolaryngol Head Neck Surg. 141: 276-283

16. Barnes L1, Ferlito A, Altavilla G, MacMillan C, Rinaldo A, Doglioni C. (1996) Basaloid squamous cell carcinoma of the head and neck: clinicopathological features and differential diagnosis. Ann Otol Rhinol Laryngol. 105: 75-82 [Crossref]

\section{Citation:}

Xiaoyan Liao, Joel B. Fontanarosa, Dongwei Zhang (2020) Collision Tumor of a Squamous Cell Carcinoma and Adenoid Cystic Carcinoma in Mobile Tongue. J Clin Res Med Volume 3(1): 1-3. 